\title{
М.Е. Лошкарева
}

\section{JOHANNA DOMINA WALLIE}

\begin{abstract}
Статья посвящена Иоанне Валлийской, незаконнорожденной дочери английского короля Иоанна Безземельного, ставшей супругой гвинедского принца Лливелина Великого. Этот брак стал поворотным моментом в истории княжества. Целью данного исследования является определение роли, которую сыграла Иоанна в политике гвинедского принца, англо-валлийских отношениях, а также возникновении правовых новелл, предопределивших судьбу княжества. Иоанна помогала Лливелину в отношениях с английской короной, выступала в качестве посла в сложных для княжества ситуациях. Главной целью Лливелина Великого, а затем и его потомков стало преодоление политической фрагментарности Уэльса. Лливелин отменил один из важнейших правовых обычаев Уэльса, не делавших различий между законнорожденными детьми и бастардами в вопросах наследования собственности и власти, с тем, чтобы обеспечить безраздельное наследование княжества его сыном от Иоанны, в жилах которого текла кровь Плантагенетов.

Ключевые слова: Иоанна Валлийская; Лливелин Великий; Гвинед; Средневековый Уэльс; англо-валлийские отношения.
\end{abstract}

Роль династических браков в политических процессах, определявших жизнь средневековой Европы, трудно переоценить. Матримониальный компонент присутствовал, как правило, в значимых событиях этой эпохи. Династические союзы в средневековом Уэльсе довольно редко становятся объектом пристального внимания исследователей [1] в силу их относительной малозначительности в сравнении с крупными монархиями Европы.

Три доминировавшие в Уэльсе династии - правителей Поуиса, Дехейбарта и Гвинеда - были довольно тесно связаны между собой матримониально, однако это не привело к созданию сколько-нибудь прочных военно-политических союзов даже перед угрозой нормандского вторжения.

После нормандского завоевания представители валлийских династий были заинтересованы в союзах с влиятельными семействами Валлийской Марки, о чем свидетельствуют их браки.

К середине XII в. Гвинед становится доминирующим княжеством в Уэльсе и активно вовлекает в орбиту своего влияния менее значительных соседей, в том числе с помощью династических браков. Сын Овайна Гвинедского Йорверт был женат на дочери правителя Поуиса Мадога ап Мередита Мараред, их сын, Лливелин ап Йорверт, вошел в историю как Великий. Йорверт ап Овайн был отстранен от наследования братьями и погиб, когда Лливелин был еще ребенком. Лливелин ап Йорверт сумел вернуть наследственные земли в Уэльсе, развязав войну с дядями по отцу. По утверждению Гиральда Камбрийского, Лливелину было только двенадцать лет, когда он начал борьбу за контроль над Гвинедом [2. Р. 453]. В результате к 1200 г. после целого ряда побед [3. Р. 75-81] большая часть княжества оказалась под его контролем. На его пути к установлению гегемонии в Уэльсе стоял правитель Поиуса Гвенвинвин ап Овайн Кэвэйлиог.

Иоанн Безземельный, ставший английским королем в 1199 г., вел тонкую политику в Уэльсе, постоянно сталкивая Лливелина и Гвенвинвина. 11 июля 1201 г. было подписано первое сохранившееся соглашение между представителями английского короля и валлийским принцем [4. Р. 371]. Согласно документу, Лливелин, в присутствии епископа Бангорского Роберта, епископа Сент Азафа Рейнера и королевского юстициария Джеффри фиц Питера, присягнул на верность королю (Иоанн вернулся в Англию из Нормандии только в 1203 г.). Лливелин получил права на земли, находившиеся на тот момент в его владении. По возвращении короля Лливелин должен был принести оммаж королю как своему сеньору. Король прощал все преступления, совершенные до заключения мира.

Поворотным моментом в истории Гвинеда, а затем и Уэльса в целом стал брак Лливелина Великого с незаконнорожденной дочерью английского короля Иоанна Безземельного Иоанной (по-валлийски ее имя передавалось как Siwan).

Целью данного исследования является определение роли, которую сыграла Иоанна в политике гвинедского принца, англо-валлийских отношениях, а также возникновении правовых новелл, предопределивших судьбу княжества.

Происхождение Иоанны - вопрос до конца не разрешенный. У короля Иоанна Безземельного помимо законнорожденных детей ${ }^{1}$ было не менее семи бастардов от разных матерей. Указание на мать Иоанны есть в хронике монастыря Тьюксбери, где есть запись о ее смерти: «Obiit domina Johanna domina Walliae uxor Lewelini, filia regis Johannis et reginae Clemenciae» [5. Vol. I. P. 101]. Это единственный известный источник, который называет имя матери Иоанны - королева Клеменция. В данном случае титул regina используется хронистом явно неправомерно: хотя Иоанна и была впоследствии признана папой Римским законной, король Иоанн Безземельный не был женат на ее матери. Предположительно, ей могла быть жена Генриха Пинела [6. Р. 76] или Клеменс де Фугерес, вторая жена Ранульфа де Блондевиля, шестого графа Честера [7. P. 299]. Еще одной возможной матерью Иоанны порой 
называют Агату де Феррерс - дочь Вильма де Феррерса, третьего графа Дерби и Сибиллы де Браоз [8. P. 433].

Предположительной датой рождения Иоанны считается 1191 г. До принятия ее отцом решения о заключении брака с Лливелином она, возможно, жила на континенте.

Лливелин ап Йорверт к этому моменту женат не был, но уже имел сына Гриффита и дочь Гвенлиан от связи (или брака, не признанного церковью) с валлийкой Тангвестл, дочерью Лливарха Гоха. Он намеревался жениться на дочери короля Мэна Рагнвальда Годредссона (вдове его дяде Родри) и испрашивал папского разрешения, которое и было получено в 1203 г., хотя папская переписка, касающаяся этого вопроса, продолжалась вплоть до начала 1205 г. [9. Р. 8, 19].

Согласно нормам валлийского права, бастарды имели равные права с законнорожденными детьми, а значит, в наследнике валлийский принц не нуждался. Отказ от брака с дочерью короля Мэна в пользу союза с англичанкой демонстрирует серьезные изменения в расстановке сил в регионе: важность взаимоотношений с северо-западными соседями вытеснялась восточным политическим вектором. Цели, которые преследовались обеими сторонами этого альянса, вполне очевидны. Для Лливелина брак с представительницей дома Плантагенетов был серьезным достижением, ибо должен был значительно повысить статус гвинедской династии: дети Иоанны были бы потомками Генриха Плантагенета и Элеоноры Аквитанской. Иоанну Безземельному, в свою очередь, важно было достичь определенной стабильности в отношениях с Уэльсом и обезопасить границы, чтобы сосредоточить усилия на континентальных и внутрианглийских проблемах его турбулентного царствования.

Брак Лливелина и Иоанны был заключен предположительно весной 1205 г. «Annales Cestrienses» датируют это событие 1204 г.: «Rex Johannes filiam suam Nocham Lewelino principi Wallie dedit et Cuma ea castellum de Hellesmer» [10. Р. 48], но этим же годом эта хроника датирует и сбор войск в Портсмуте, имевший место в 1205 г., согласно «Flores Historiarum» Роджера Уэндовера [11. Р. 215]. Хроники монастыря Вигорн («Annales de Wigornia») датируют этот брак 1206 г., хотя это и маловероятно: «Lewelinus desponsavit filiam regis post Ascensionem» [5. Vol. IV. P. 394]. В качестве приданого Иоанны Лливелин получил замок Эллесмер, [Ibid. Vol. I. P. 48], принадлежавший ранее дяде Лливелина Дэвиду ап Овайну, умершему в 1203 г. [3. Р. 82] ${ }^{2}$.

Очевидно, Иоанна помогала супругу в делах с тестем и отношения на какое-то время наладились. Крупных военных кампаний не случалось вплоть до 1211 г. Роль Иоанны в политике гвинедского принца трудно переоценить, но помимо политических этот брак повлек за собой определенные культурные и правовые новеллы. Влияние Иоанны отразилось в текстах Закона Хауэла Доброго ${ }^{3}$, созданных в этот период в
Гвинеде. Древнейшей, определенно созданной еще в донорманнский период, частью Закона является раздел, посвященный королевскому двору. В рукописях редакции Йорверта, определенно связанной с Гвинедом и отражающей влияние Лливелина ап Йорверта, корпус норм несколько отличается от двух других редакций, и даже столь консервативная часть обычая, как придворный этикет и привилегии, видимо, подверглась модернизации в рассматриваемый период. Так, в редакции Йорверта увеличено количество чиновников королевы, что явно демонстрирует особый статус супруги Лливелина ап Йорверта [12. Р. 28-31].

Короля не могло не беспокоить возрастающее могущество гвинедского принца. В 1210 г. он восстановил права Гвенвивина на земли южного Поуиса [3. Р. 84]. Это было прямым вызовом Лливелину. Согласно «Хронике принцев», в ответ на атаки Лливелина король Иоанн, при поддержке Гвенвинвина и других принцев, Поуиса и Дехейбарта, вторгся в Гвинед, но потерпел поражение и вынужден был отступить из-за голода. Новая королевская кампания, начавшаяся в августе 1211 г., была подготовлена куда лучше и была успешной. В результате англичанами был сожжен Бангор, а епископ взят в плен (он впоследствии был выкуплен) [Ibid. P. 85]. Хронист утверждает, что Лливелин не справился с натиском короля и по совету своих приближенных послал на переговоры о мире Иоанну [Ibid.]. Лливелин получил охранную грамоту, явился к королю и по условиям мира уступил Перфедалад (северо-восточные земли), выдал заложников «столько, сколько пожелает король», в том числе старшего сына Гриффита, ${ }^{4}$ и выплатил значительную контрибуцию. Лливелин также гарантировал переход его владений короне в случае, если у него не будет наследников от брака с дочерью короля [4. Р. 387]. Этот договор имел огромное значение, и не только потому, что демонстрировал шаткость положения гвинедского принца. Весьма показательна роль Иоанны в этом соглашении. Она, по-видимому, не только выступила в качестве посла принца, но и попыталась гарантировать будущее своих возможных детей. Король получил ценного заложника в лице Гриффита, и, несмотря на то что он впоследствии был освобожден согласно «Великой хартии вольностей», Иоанна сделала все, чтобы устранить его от наследования. Гриффит в итоге получил собственный удел, но значительную часть жизни провел в заключении (супруга Гриффита леди Сенана обращалась к Генриху III с просьбой о его освобождении, но безуспешно) [Ibid. P. 452].

Иоанн начал активное строительство замков в Уэльсе, и многие валлийские лорды, бывшие до сих пор его союзниками, заключили мир с Лливелином [3. Р. 86]. В августе 1212 г. Иоанн отдал приказ о казни двадцати восьми валлийских заложников в ответ на мятеж Лливелина. Согласно Роджеру Уэндоверу, он получил секретное письмо от Иоанны о том, что, продолжая антиваллийскую кампанию, король подвергает 
себя опасности и может быть даже убит баронами [4. Р. 445]. Лливелин в этот период получил поддержку папы Иннокентия III: воспользовавшись тем, что понтифик находился в состоянии продолжительного конфликта с английским королем, он получил освобождение от присяги королю и интердикта [3. Р. 87].

Лливелин ап Йорверт, очевидно не без помощи супруги, сумел наладить отношения со всеми соседями; его дети заключили браки с представителями влиятельных семейств. Эти браки были нацелены на упрочение позиций Гвинеда и развитие связей с Маркой.

Мир с королем, заключенный в Вустере в 1218 г., закрепил обширные территориальные приобретения Лливелина. Кармартена и Кардиган оставались за валлийским принцем до совершеннолетия короля Генриха III. Лливелин получил право вершить суд в указанных землях над англичанами согласно английскому праву, а над валлийцами - согласно валлийскому [4. Р. 399]. Начался период относительного мира в англо-валлийских отношениях, хотя и не без периодических кампаний, связанных с активной деятельностью регента Генриха III Губерта де Бурга [3. Р. 103].

Лливелин был бесспорным лидером в Исконном Уэльсе, и в 1230 г. он принял титул принца Аберффрау и лорда Сноудона (princeps Aberfrau, dominus Snawdini) [4. Р. 422], до этого он именовал себя только принцем Северного Уэльса (princeps Norwallie). Новый титул отражал основу его власти, ассоциируя его верховенство с традиционным центром власти в Гвинеде. Прочие валлийские лорды прекратили к этому времени именовать себя королями и принцами. Заметим, что вопрос о титуле гвинедских принцев был одним из ключевых в англо-валлийских отношениях. В хрониках Иоанна никогда не именуется принцессой, ее чаще называют дочерью короля Иоанна («filia regis Johannis», по-валлийски Siwan ferch Jeuan ) или женой Лливелина («uxor Lewelini», по-валлийски gwreic Llywelyn). В переписке и некоторых хрониках она именуется «domina Wallie» [Ibid. P. 447]. Титул «domina Wallie» был, вероятнее всего, воспринят Иоанной после 1230 г., и, что важно, был признан английским королем Генрихом III.

Одной из важнейших задач Лливелина стало обеспечение безраздельного наследования созданного им княжества. В этом вопросе влияние Иоанны представляется несомненным. Из двух сыновей принца (незаконного Гриффита и Дэвида от Иоанны), разумеется, был выбран Дэвид. Однако существовало серьезное препятствие: Закон Хауэла Доброго. Согласно валлийскому праву, бастарды, признанные отцами, имели право на имя отца, его опеку, наследовали имущество и власть [12. Р. 131]. Лливелин отменил этот обычай как «противный закону божественному и человеческому» («juri divino et humano contrariam») в 1220 г. с согласия короля Генриха III и епископа Кентерберийского Стефана. В 1222 г. папа Гонорий III утвердил его постановление [4. Р. 415]. Заметим, что, несмотря на волю принца, подкрепленную решением понтифика, текст Закона содержит указание на то, что норма о равноправии бастардов и законнорожденных не может быть проигнорирована [12. Р. 132]. Лливелин ап Йорверт стремился решить вопрос наследования еще при жизни, поэтому сделал все для того, чтобы Дэвида признали валлийские лорды, король и папа.

В апреле 1226 г. по просьбе Лливелина ап Йорверта папа Гонорий III признал Иоанну законной дочерью Иоанна Безземельного без права на наследование английского престола. Обосновывая решение, понтифик указал, что он удовлетворяет просьбу гвинедского принца, дабы не страдала честь Лливелина и его сына Дэвида, а также в силу его преданности Церкви [13. Р. 417].

После смерти своего отца Иоанна продолжала выступать посредником в отношениях Лливелина и английского короля. До нас дошла ее переписка с Генрихом III. В одном из писем (датируемом 1230-1231 гг.) она выражает беспокойство по поводу того, что ее враги и, разумеется, враги короля сеют вражду между ее мужем и Генрихом, уверяет его в верности Лливелина и предупреждает о том, как опасно терять преданных союзников [4. Р. 447].

В 1230 г. происходит из ряда вон выходящее событие, освещенное в «Хронике принцев»: Иоанна была уличена в связи с Уильямом де Браозом, лордом Брекона [3. Р. 102]. Уильям де Браоз был пленен в ходе королевской кампании в Уэльсе в 1228 г. [3. Р. 101]. Одним из условий его освобождения было заключение брака между наследником Лливелина Дэвидом и дочерью Уильяма Изабеллой [5. Vol. III. Р. 117]. Отношения между Иоанной и де Браозом возникли, видимо, еще в период его заключения. Лорда Брекона посещал двор Лливелина на пасхальной неделе 1230 г., и во время его визита он, по утверждению хрониста, был схвачен в покоях Иоанны. Уильям де Браоз был приговорен к смерти и 2 мая 1230 г. повешен на дереве в Крогене в присутствии восьмисот человек (описание его казни содержится в письме настоятеля цистерцианского аббатства Водей к канцлеру Ральфу Невиллу) [14. Р. 37]. Заметим, что брак Дэвида с Изабеллой де Браоз, несмотря на столь исключительные обстоятельства, не расстроился. В письме к жене казненного Уильяма де Браоза Еве Лливелин, выясняя ее намерения относительно брака Дэвида и Изабеллы, подчеркивает, что он не мог предотвратить казни, ибо это было решение его магнатов, а не его личное [4. Р. 428].

Супружеская измена, согласно валлийскому праву, была основанием для расторжения брака [12. Р. 48], но Лливелин, совершенно очевидно, не пытался этого сделать. И дело не только в том, какую роль играла сестра английского короля в гвинедской политике, Лливелин был, очевидно, искренне привязан к ней. Заключение Иоанны, последовавшее в качестве наказания, продолжалось недолго. В 1231 г. Иоанна была прощена супругом: «Lewelinus princeps Wallye recepit uxorem suam filiam Johannis regis quam antea incarceravit» [10. P. 56]. 
В 1232 г. она уже представляла его интересы в Шрусбери на переговорах с Генрихом III [15. Р. 476]. С 1232 по 1237 г. между гвинедским принцем и королем было заключено несколько соглашений о перемириях, постоянно нарушаемых сторонами [4. Р. 433-434].

В феврале 1237 г. Иоанна скончалась в резиденции Лливелина в Абере [3. Р. 104]. Уход из жизни супруги был тяжелейшей утратой для Лливелина, Иоанна играла огромную роль как в жизни принца, так и в судьбе княжества. По утверждению хрониста, она была похоронена на берегу моря в Лланфаэс на Англси, где позднее Лливелином было построено францисканское аббатство в честь его почившей супруги. Монастырь был разрушен в 1537 г., и могила Иоанны была утрачена.

Год смерти Иоанны стал роковым для Лливелина Великого: в 1237 г. умер его зять - Джон Скот, граф Честер (если доверять Мэтью Парижскому, он был отравлен дочерью принца Элен) [16. Р. 54]. Лливелин тяжело заболел, фактическим правителем княжества стал Дэвид. В 1238 г. на собрании валлийских лордов в аббатстве Страта Флорида Дэвиду была принесена присяга [3. P. 104]. Лливелин Великий умер в апреле 1240 г. [Ibid. Р. 105]. Дэвид, унаследовавший княжество, не сумел закрепить достижения отца и в 1246 г. умер, не оставив наследников [Ibid. P. 107]. По иронии судьбы княжество Уэльс будет объединено Лливелином Последним, сыном Гриффита ап Лливелина, лишенного права наследования в пользу потомка Плантагенетов Дэвида.

В церкви Святых Марии и Николая в Бомарисе (Англси) можно увидеть каменный саркофаг, табличка над которым гласит: «Этот скромный саркофаг (однажды удостоенный останков Иоанны, дочери короля Иоанна и супруги Лливелина ап Йорверта, Принца Северного Уэльса, которая умерла в 1237 г.) был перенесен из Лланфаэса и, увы, много лет использовался для того, чтобы поить лошадей, теперь избавлен от такого пренебрежения и помещен здесь для сохранения и побуждения раздумий о бренности бытия Томасом Уорреном Балкли. Октябрь 1808 г.».

Несмотря на то что сомнения по поводу того, действительно ли в этом саркофаге покоились останки Иоанны, не лишены оснований, церковь в Бомарисе является местом паломничества, потому что связано с Siwan, одной из важнейших фигур в валлийской средневековой истории.

Иоанна, бесспорно, сыграла выдающуюся роль в истории княжества Уэльс. Ее заслугой было временное ослабление напряженности в англо-валлийских отношениях, позволившее гвинедскому принцу Лливелину ап Йорверту достичь бесспорного лидерства в регионе. Главной целью Лливелина Великого, а затем и его потомков стало преодоление политической фрагментарности Уэльса, обусловленной во многом особенностями правовой системы. Отмена валлийского обычая, касавшегося наследственных прав бастардов, с целью обеспечения безраздельного наследования княжества может объясняться влиянием Иоанны. Изменения, внесенные в текст Закона Хауэла Доброго, отражали беспрецедентно высокий статус супруги Лливелина Великого.

\section{ПРИМЕЧАНИЯ}

\footnotetext{
${ }^{1}$ У короля Иоанна Безземельного была и законная дочь от брака с Изабеллой Ангулемской с именем Иоанна - она стала женой Александра II Шотландского.

${ }^{2}$ Дэвид ап Овайн был женат на незаконнорожденной сводной сестре Генриха II Эмме.

${ }^{3}$ Национальная правовая система Уэльса в период Средневековья была связана с Законом Хауэла Доброго (по-валлийски - Суfraith Нуwеl, полатыни - Leges Hoeli). Традиция приписывает создание закона валлийскому королю Хауэлу (Х в.), хотя значительная часть правового материала относится скорее к XII-XIII вв. Закон Хауэла оставался единственным источником права до введения Эдуардом I Хритланского статута.

${ }^{4}$ Гриффит ап Лливелин был возвращен вместе с другими заложниками согласно «Великой хартии вольностей».
}

\section{ЛИТЕРАТУРА}

1. Roderick A.J. Marriage and politics in Wales, 1066-1282 // Welsh History Review. 1968. Vol. 4, № 1. P. 3-20.

2. The Historical Works of Giraldus Cambrensis / ed. by T. Wright. L., 1863.

3. Brut y Tyvysogyon or The Chronicle of the Princes. Peniarth MS. 20 Version / transl. by Thomas Jones. Cardiff : University of Wales Press, 1952.

4. The Acts of Welsh Rulers 1120-1283 / ed. by H. Pryce. Cardiff, 2005.

5. Annales Monastici. Vol. I / ed. by Henry Richard Luard. L., 1864.

6. Weir A. Britain's Royal Families. The Complete Genealogy. L., 1989.

7. Swallow R. Gateways to Power: The Castles of Ranulf III of Chester and Llywelyn the Great of Gwynedd // Archaeological Journal. 2014 . Vol. 171. P. 291-314.

8. Dennis M.D. The family. Vol. 1. P. 433. URL: http://www.electricscotland.com/webclans/minibios/c/family_book_voli.pdf

9. Calendar of Entries in the Papal Registers Relating to Great Britain and England. Papal Letters. Vol. I. A.D. 1198-1304 / ed. by W.H. Bliss. L., 1893.

10. Annales Cestrienses or Chronicle of the Abbey of S. Werburg at Chester / ed. Christie R.C. Vol. 14. L. : Record Society of Lancashire and Cheshire, 1887.

11. Roger of Wendover's Flowers of History. Comprising the History of England from the Descent of the Saxons to A.D. 1235. Formerly ascribed to Matthew Paris / trans. by J.A. Giles. L., 1849. Vol. 1.

12. The Law of Hywel Dda / transl. and ed. by D. Jenkins. Llandysul, Ceredigion, 2000.

13. Regesta Honorii Papae III / ed. by P. Pressutti. Rome, 1885. Vol. II.

14. Calendar of Ancient Correspondence Concerning Wales / ed. by J. Goronwy Edwards. Cardiff, 1935.

15. Patent Rolls of the Reign of Henry III Preserved in the Public Record Office A.D. 1225-1232. L., 1908.

16. Matthew Paris's English History From the Year 1235 to 1273 / transl. by J.A. Giles. L., 1852. Vol. I.

Loshkareva Maria E. National Research University Higher School of Economics (Moscow, Russia). E-mail: mloshkareva@hse.ru JOHANNA DOMINA WALLIE.

Keywords: Joan; Lady of Wales; Llywelyn The Great; Gwynedd; Medieval Wales; Anglo-Welsh relationship. 
The article is devoted to Joan, Lady of Wales (also known by her Welsh name as Siwan), English king John Lackland's illegitimate daughter married prince of Gwynedd Llywelyn ap Iorwerth in 1205. Their dynastic marriage obviously had a great impact on Gwynedd policy and the Anglo-Welsh relationship of $13^{\text {th }}$ century. The aim of the research is to define the role played by Joan in the most significant aspects of Llywelyn the Great's policy by means of analyzing such historical sources as Welsh and English chronicles, including The Chronicle of the Princes, Roger of Wendover's Flowers of History, Annales Monastici etc, corpus of Welsh native law texts, known as The Law of Hywel Dda, some legal acts and official correspondence, concerning Wales. One of the most controversial questions in the current historiography is Joan's ancestry. The only mention of Joan's mother can be found in the Tewksbury annals where she is referred to as "regina Clemencia". However, without any doubt she was not of royal blood and had never been married to John Lackland. Joan was only legitimized by pope Honorius III in 1226 at Llywelyn's request. The reasons behind John's and Llywelyn's agreement to this marriage are open to debate. As a result of his marriage to the English king's daughter, Llywelyn's descendants were supposed to acquire blood relationship to the Plantagenets, one of the most powerful dynasties in Europe. King John had political stake in this marriage: he hoped that the reduced Welsh threat on the border would allow him to focus on more important issues of his reign such as continental troubles and concerns with the baronial confrontation. It is hard to overrate the role Joan played in the Welsh policy. Having married the prince of Gwynedd, Joan became an extremely efficient intermediary between the Welsh and the English crown. She repeatedly acted as an ambassador of the Welsh prince in negotiation with her father king John and her half-brother king Henry III. Even though Llywelyn the Great adopted the title of Prince of Aberffraw and Lord of Snowdon, Joan was never called "Princess" in the documents, as her title, recognized by Henry III, was "Lady of Wales". Joan's influence in the matter of some important cultural and legal innovations in Wales looks undeniable, e.g. Llywelyn ap Iorwerth abolished an ancient Welsh legal custom, according to which there was not any difference between legitimate sons and bastards in matters relating to inheritance, in order to make Joan's son Daffyd, the only heir to the Gwynedd throne. Despite not being a native Welsh, Siwan is considered to be one of the most prominent heroic figures of Medieval Wales due to her remarkable life and the significant role she played in the formation of the Principality of Wales.

\section{REFERENCES}

1. Roderick, A.J. (1968) Marriage and politics in Wales, 1066-1282. Welsh History Review. 4(1). pp. 3-20.

2. Wright, T. (1863) The Historical Works of Giraldus Cambrensis. London: Bohn.

3. Brut Y Tywysogyon or The Chronicle of the Princes. Peniarth MS. 20 Version. Translated by Th. Jones. Cardiff: University of Wales Press.

4. Pryce, H. (ed.) (2005) The Acts of Welsh Rulers 1120-1283. Cardiff.

5. Luard, H.R. (eds) (1864) Annales Monastici. Vol. I. London: [s.n.].

6. Weir, A. (1989) Britain's Royal Families. The Complete Genealogy. London: Random House.

7. Swallow, R. (2014) Gateways to Power: The Castles of Ranulf III of Chester and Llywelyn the Great of Gwynedd. Archaeological Journal. 171. pp. 291-314. DOI: 10.1080/00665983.2014.11078268

8. Dennis, M.D. (n.d.) The Family. Vol. I. pp. 433. [Online] Available from: http://www.electricscotland.com/webclans/minibios/c/family book voli.pdf.

9. Bliss, W.H. (ed.) (1893) Calendar of Entries in the Papal Registers Relating to Great Britain and England. Papal Letters. Vol. I. London: H.M. Stationery Off.

10. Christie, R.C. (ed.) (1887) Annales Cestrienses or Chronicle of the Abbey of S. Werburg at Chester. Vol. 14. London: Record Society of Lancashire and Cheshire.

11. Anon. (1849) Roger of Wendover's Flowers of History. Comprising the History of England from the Descent of the Saxons to A.D. 1235. Formerly ascribed to Matthew Paris. Translated by J.A. Giles. Vol. 1. London.

12. Jenkins, D. (ed.) (2000) The Law of Hywel Dda. Llandysul, Ceredigion.

13. Pressutti, P. (ed.) (1885) Regesta Honorii Papae III. Vol. II. Rome: By Typographia Vaticana.

14. Goronwy Edwards, J. (ed.) (1935) Calendar of Ancient Correspondence Concerning Wales. Cardiff: University Press Board.

15. Anon. (1908) Patent Rolls of the Reign of Henry III Preserved in the Public Record Office A.D. 1225-1232. Lonond: H.M. Stationery Office.

16. Paris, M. (1852) English History From the Year 1235 to 1273. Translated by J.A. Giles. Vol. I. London: H.G. Bohn. 